The Chittagong Univ. J. B. Sci., Vol. 3(1 \&2): pp. 149-160, 2008.

\title{
PEOPLE'S PERCEPTION ON URBAN TRAFFIC CONGESTION: A CASE STUDY ON CHITTAGONG METROPOLITION CITY, BANGLADESH
}

SHAHEK MOHIUDDIN MD. ALAMGIR AL-QADERY AND MD. MUHIBBULLAH *

Department of Geography and Environmental Studies, University of Chittagong, Chittagong4331, Bangladesh.

\begin{abstract}
An attempt has been taken to identify the major causes of traffic congestion along with existing system deficiencies, their consequences, and finally a policy options are recommended on Chittagong Metropolitan City. For the study primary data were collected through questionnaire survey and secondary data were used from various sources. The collected data were analyzed by using statistical techniques. It was found that rapid growth of population, inefficient land use pattern, indiscriminate roadside uses, past urban development trends and inadequate land use planning are responsible for traffic congestion in the city area. Lack of coordination and integration of concerned institutions is one of the major system deficiencies of traffic congestion situation in the study area. Opinion survey revealed that the overall quality of transportation system of Chittagong city is unsatisfactory.
\end{abstract}

Key words: Perception, urban, traffic, congestion.

\section{INTRODUCTION}

The state of being crowded and full of traffic in a particular transport node is called traffic congestion (Anon 2003). Traffic congestion occurs when urban transport network is no longer capable of accommodating the volume of movements of vehicles that use them. Any large or medium size city will be aware of the traffic congestion problems for the total transport system (Brian and Richard 1986). Congestion causes increase of cost for travelers and freight movement, loss of time and psychological strain. There are several generic causes of traffic congestion. Among them rapid growth of urbanization come first, imbalance of supply and demand of transportation infrastructure is the second, and lack of traffic management schemes is the most important reason behind traffic congestion (Nishad 2002). Although such congestion may originate at a

\footnotetext{
* Corresponding author.
} 
particular point or transport node but it may also spread along other streets which are finally responsible for build-up of a traffic delay over a wide area (Barua 2007). Thus a single bottleneck may affect traffic flow over a considerable area. Congestion is also related to the pattern of land use in the urban area. The location of congested area is determined by the physical transport framework and by the patterns of urban land use (Chowdhury 1986). The levels of traffic overloading vary in time, well-marked peak hour during the daily journey for the daily working periods. Chittagong city is not only the principal city of Chittagong division but also the second largest city of Bangladesh. The total population of Chittagong city is near about 3.5 million and its rate of urbanization is $4.5 \%$ (Karim 2000). As a result, a large number of various vehicles are increasing rapidly due to expansion of urbanization, commercial activities and industrial development in the city. Traffic congestion is increasing day by day and it is affecting the daily life of its citizens. Identifying the causes and consequences of congestion in Chittagong Metropolitan City, which is the main port city and commercial capital of the country, seems to be important. The present work was undertaken with the following objectives:

1. To identify degree and causes of traffic congestion in Chittagong Metropolitan City area.

2. To identify the factors and system deficiencies of the transport system responsible for traffic congestion, and

3. To know people's perception and level of satisfaction on traffic congestion

\section{MATERIALS AND METHODS}

\section{Study area}

Six traffic congested points or nodes of Chittagong Metropolitan area were selected for the case study. They are 1.Chawkbazar, 2. Sholoshahar (Gate No. 2), 3. GEC 4. New market 5. Bahaddarhat and 6. Dewan Hat (Map.1). These points are selected because they remain often crowded and congested. 
PEOPLE'S PERCEPTION ON URBAN TRAFFIC CONGESTION

MAP 1. CHITTAGONG METROPOLITAN CITY WITH STUDY AREA

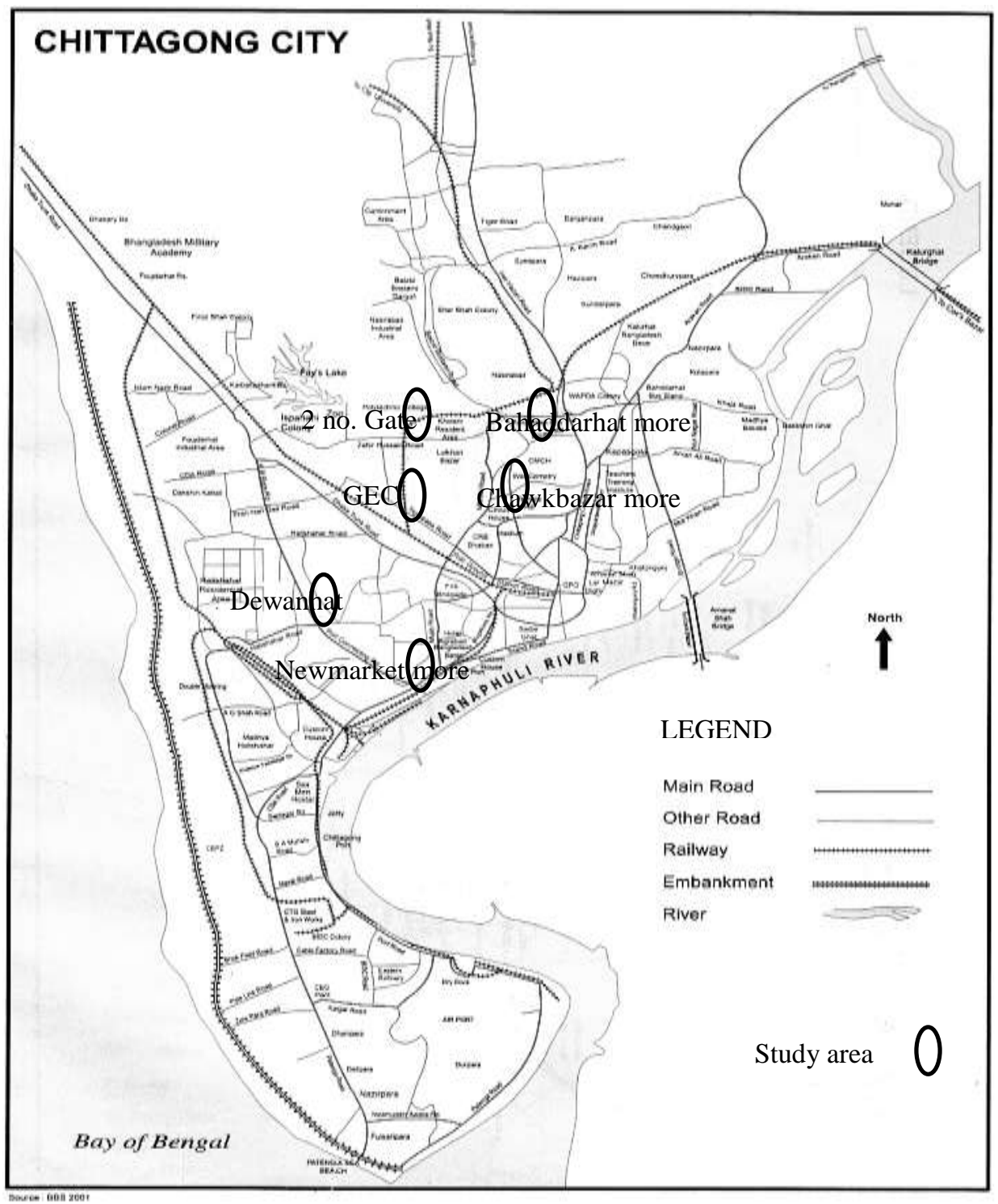

Description of the study area

Location and area

Chittagong City is situated within $22^{\circ}-14^{\prime}$ and $22^{\circ}-24^{\prime}-30^{\prime \prime} \mathrm{N}$ Latitude and between $91^{\circ}-46^{\prime}$ and $91^{\circ}-53^{\prime}$ E Longitude and on the Right Bank of the River 
Karnafuli. The area of Chittagong district is 5283 sq. $\mathrm{km}$ and the total area of Chittagong City Corporation is 97 sq. km (BBS 2007). Chittagong Municipality area is bounded on the west by the Bay of Bengal and it consists with twelve Thana and small portion of Hathazari Upazila.

\section{Topography}

Chittagong is very much different in terms of topography from other parts of the country. It is composed of scattered hillocks and palins forming a complex topographical entity. There is a peak in the city known as Batali Hill, which is 86 $\mathrm{m}$ in height and is the highest point in the town (Banglapedia 2003).

\section{Climate}

The climate of Chittagong may be described as subtropical in character for about two thirds of the year (Mid-March to October). During this period it has high temperature and humidity and a dry season following heavy rains. November to February is generally pleasant and cool with low humidity and very little rain. The average temperature during winter is $16^{\circ} \mathrm{C}$ and in summer is $29^{\circ} \mathrm{C}$. The climate of Chittagong is thus moist, warm summer and equable (Banglapedia 2003).

\section{Road Network}

Roads of this old city are very much congested specially in old city area. At present, some modern wide roads have been constructed in the newly built areas. Three modern highways connect the city with other parts of the country. One is the Dhaka-Chittagong Trunk road towards the north-west from city center. Another road, Hathazari road, connects Chittagong city with the Hathazari, Nazirhat and Fatikchari. The Arakan road joins the city with Cox`s Bazar and Teknaf towards the south. The Dhaka- Chittagong trunk road is important because it links the Chittagong Port with other parts of the country. In the old city area like Fireengi Bazar, Patharghata, Ashadgonj, Khatungonj, Chaktai etc. roads are very much congested and unplanned. Those areas are important for business and wholesale market of the city.

\section{Sources of Data}

For this study both primary and secondary data have been used.

(a) Primary sources

It includes field survey and road user survey through questionnaire.

\section{(i) Field survey}




\section{PEOPLE'S PERCEPTION ON URBAN TRAFFIC CONGESTION}

For field survey a number of experts in the transportation field were personally interviewed. This information was matched with the secondary data to study the reliability of the primary data.

(ii) Road user opinion survey through questionnaire

To incorporate peoples' understanding about traffic congestion, a set of questionnaire was prepared and produced directly to the people of the research area and their views were collected. The sample size was 300 questionnaires. The road user opinion survey through questionnaire includes the characteristics of the respondent, purpose of trip, behavioral pattern towards traffic rules and regulations, degree and nature of traffic congestion, causes of traffic congestion, system deficiencies responsible for traffic congestion.

(b) Secondary sources

Many published or unpublished articles related to the research work were frequently consulted for the study. Among them, reports published by Chittagong City Corporation (CCC), Chittagong Development Authority (CDA), Department of Environment (DOE), and many other non-governmental organizations have been studied. Besides these, the related old records of different offices and the news from daily newspaper have been utilized.

Data analysis

The collected data have been processed for tabulation and graphical presentation.

\section{Index of satisfaction}

To determine the limit of satisfaction and dissatisfaction of the different transport related variables, the following satisfaction index developed by Hall et al. (1975) was used.

$$
\begin{aligned}
& I_{s}=\frac{f_{s}-f_{d}}{N} \\
& \text { Here, }, \mathrm{I}_{\mathrm{s}}=\text { Satisfaction Index. } \\
& \mathrm{f}_{\mathrm{s}}=\text { Number of Satisfied respondents. } \\
& \mathrm{f}_{\mathrm{d}}=\text { Number of dissatisfied respondents } \\
& \mathrm{N}=\text { Total Number of respondents. } \\
& \text { The value of the index ranged from }+1 \text { to }-1 .
\end{aligned}
$$


AL-QADERY \& MUHIBBULLAH.

\section{RESULTS AND DISCUSSION}

\section{Major causes and nature of traffic congestion}

In the present study the major causes of traffic congestion in the study area have been identified. Uncoordinated and non-integrated character of existing concerned institutions is one of the major system deficiencies of the overall traffic congestion. Although the carriageway width of existing road is adequate, traffic congestion occurs in almost all the junctions and roads in the Chittagong city. Table 1 shows the major causes of traffic congestion according to the opinion of the respondents. The main cause of traffic congestion in the study area is indiscriminate parking and stopping of vehicle in and around junctions (21.67\%). Other causes are absence of traffic law enforcement (14.66\%), indiscriminate overtaking and road space occupation (11.67\%), road construction (9.67\%), maximum educational institutions and filling stations beside busy roads $(9.67 \%)$ and poor signal system $(6 \%)$.

From the Table 1 and consultation with transport experts and also from various secondary sources (News paper, Articles, etc) the identified causes of traffic congestion in the Chittagong city can be divided into five categories. They are as follows:

(1) Transportation network related causes

It includes with non-integration of road network, absence of road hierarchy, poor intersection which are creating huge traffic congestion in the city.

(2) Land use and planning related causes

It is comprises with rapid growth of population and deficient land use pattern, indiscriminate roadside land uses, historical urban development trend and inadequate land use planning.

TABLE 1. MAJOR CAUSES OF TRAFFIC CONGESTION IN THE STUDY AREA.

\begin{tabular}{lcc}
\hline \multicolumn{1}{c}{ Nature of causes } & Frequency & Percentage \\
\hline Absence of traffic law enforcement & 44 & 14.66 \\
Indiscriminate parking and stopping of vehicle in and around & 65 & 21.67 \\
junctions. & & \\
Indiscriminate overtaking and road space occupation. & 35 & 11.67 \\
Absence of one way road system and divider in some road points & 29 & 9.67
\end{tabular}




\section{PEOPLE'S PERCEPTION ON URBAN TRAFFIC CONGESTION}

Location of shopping center and market, maximum educational institutions, $\mathrm{CNG}$ filling station etc. beside busiest road side and in some cases both sides of some busiest road points.

All small vehicles (Rickshaw auto rickshaw or baby taxi, tempo,

bus, human hauler etc.) are plying together on all roads and routs.

Poor signal design

Poor footpath facilities

Absence of planned road network

(3) Traffic characteristics related causes

Traffic characteristics related causes encompass operation of mixed speed vehicles, excessive dependence on rickshaws, absence of reliable mass transit, poor public transport system, etc.

(4) Traffic management and operational causes

Traffic management related causes consist of absence and improper use of physical devices and poor enforcement of traffic rules and regulations. Traffic operational causes include poor behavioral pattern of road users, unauthorized and indiscriminate parking, usage of road space for non transportation purposes, deficient bus route planning, etc.

(5) Institutional causes

Institutional causes depend on uncoordinated and non-integrated institutions. It is one of the major system difficulties of the traffic congestion situation.

\section{Major system deficiencies}

The major system deficiencies responsible for traffic congestion in Chittagong city include traffic management and control system (61.33\%), adequate road network (22\%), traffic characteristics (14.67\%) and institutional (2\%) (Fig. 1). 
AL-QADERY \& MUHIBBULLAH.

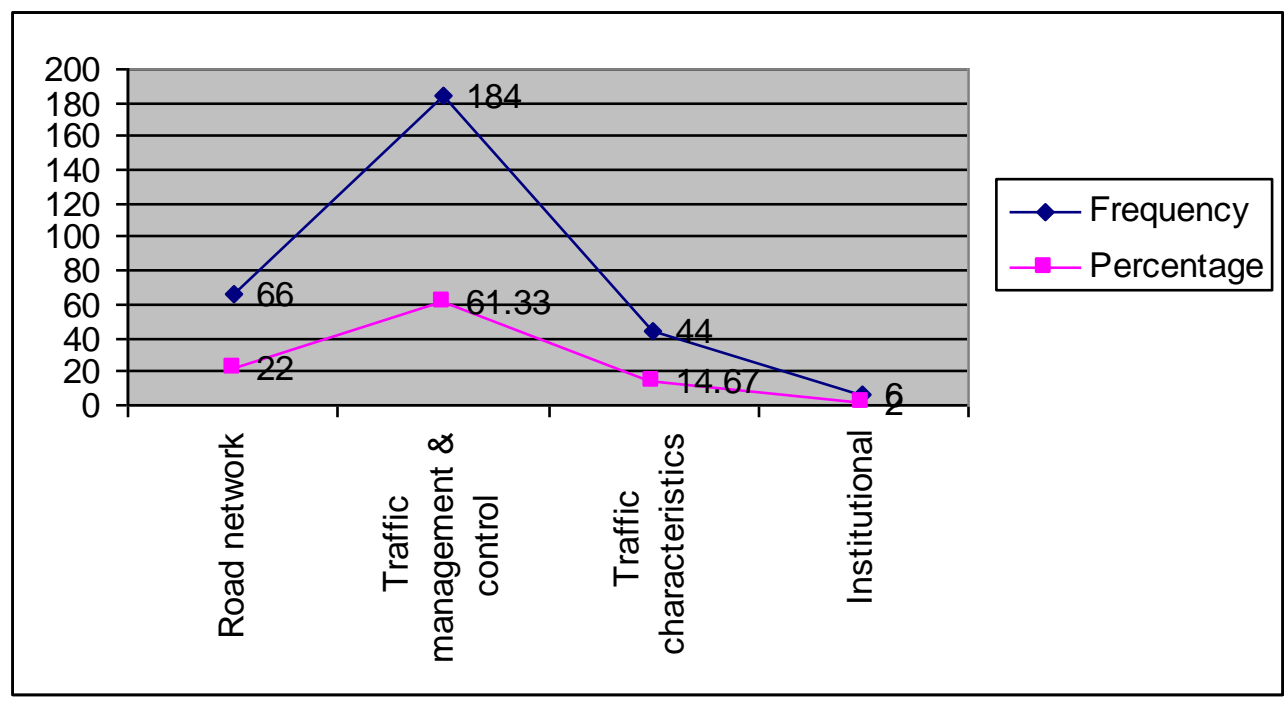

FIGURE 1. MAJOR SYSTEM DEFICIENCIES IN THE STUDY AREA.

\section{Perception of degree of traffic congestion}

About $98 \%$ of the total respondents have given their opinion positively that there is available traffic congestion in the Chittagong Metropolitan City. The degree of traffic congestion was heavy, moderate and light according to 53, 42 and $5 \%$ respondents respectively (Fig. 2).

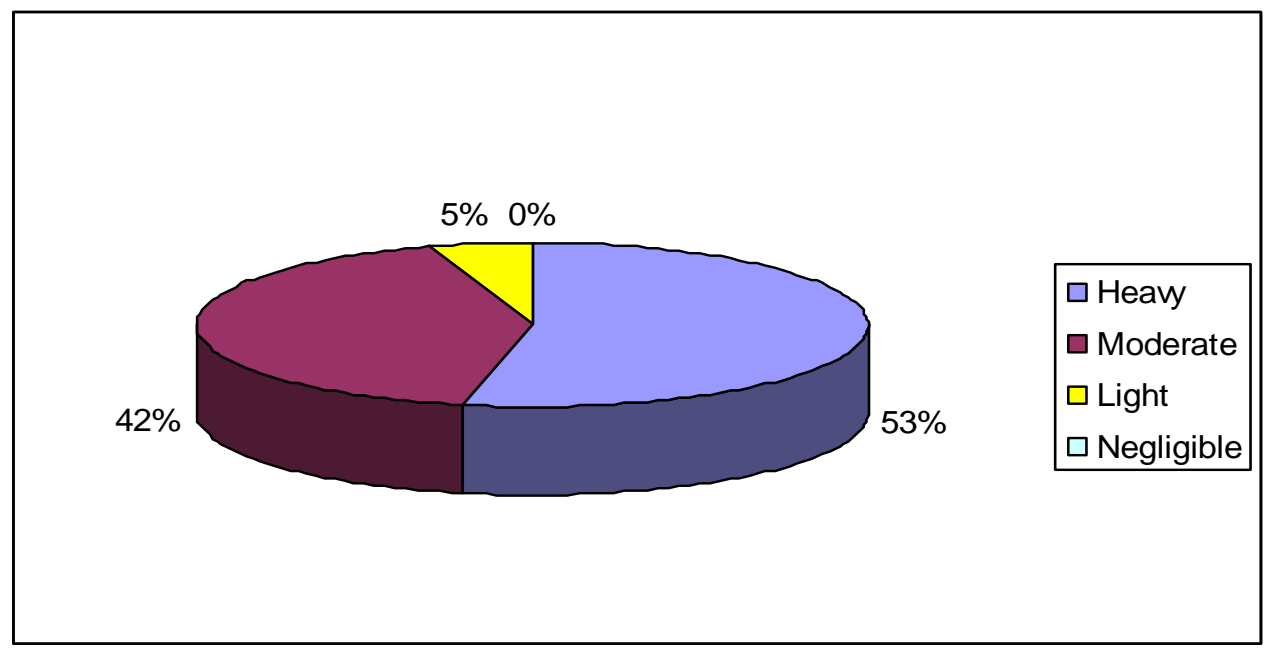

FIGURE 2. DEGREE OF TRAFFIC CONGESTION IN THE STUDY AREA. 
PEOPLE'S PERCEPTION ON URBAN TRAFFIC CONGESTION

Time variation of traffic congestion

According to road user's opinion survey 53\% respondent face congestion during $9.00 \mathrm{am}$ to1.00pm, 34\% from $5.00 \mathrm{pm}$ to $9.00 \mathrm{pm}$ and $3 \%$ face traffic congestion from $3.00 \mathrm{pm}$ to $5.00 \mathrm{pm}$ (Table 2). The periods between $9.00 \mathrm{am}$ and $11.00 \mathrm{am}$ and from $5.00 \mathrm{pm}$ to $7.00 \mathrm{pm}$ are the peak periods when most of the people are travel for official, commercial and educational purposes.

TABLE 2. TIME VARIATION OF TRAFFIC CONGESTION IN THE STUDY AREA.

\begin{tabular}{ccc}
\hline Time interval & Frequency & Percentage \\
& & 31 \\
$9.00 \mathrm{am}-11.00 \mathrm{am}$ & 93 & 22 \\
$11.00 \mathrm{am}-1.00 \mathrm{pm}$ & 66 & 08 \\
$1.00 \mathrm{pm}-3.00 \mathrm{pm}$ & 24 & 03 \\
$3.00 \mathrm{pm}-5.00 \mathrm{pm}$ & 9 & 24 \\
$5.00 \mathrm{pm}-7.00 \mathrm{pm}$ & 72 & 10 \\
$7.00 \mathrm{pm}-9.00 \mathrm{pm}$ & 10 & 02 \\
Others & 06 & \\
\hline
\end{tabular}

Ranking of the traffic congested areas

According to road user opinion survey Chawkbazar is the most traffic congested area. The second place is Bahaddarhat, followed sequentially by New market, Sholoshahar (Gate No. 2), GEC, Dewanhat, Agrabad, and Oxygen (Table $3)$.

TABLE 3. RANKING OF THE MOST TRAFFIC CONGESTED POINTS IN THE STUDY AREA. (In Percentages)

\begin{tabular}{lrrrrrrr}
\hline Road Point & First & Second & Third & Fourth & Fifth & Sixth & Seventh \\
& & & & & & & \\
\hline Bahaddarhat & 26.67 & 13.33 & 21.67 & 16.67 & 11.67 & 1.67 & 0 \\
Muradpur & 0 & 0 & 5 & 5 & 0 & 1.67 & 0 \\
Gate No. 2 & 5 & 16.67 & 13.33 & 23.33 & 16.67 & 1.67 & 1.67 \\
GEC & 3.33 & 5 & 21.67 & 16.67 & 26.67 & 0 & 3.33 \\
Tiger pass & 0 & 1.67 & 0 & 5 & 0 & 0 & 0 \\
New market & 6.67 & 35 & 18.33 & 10 & 5 & 3.33 & 0 \\
Agrabad & 1.67 & 0 & 1.67 & 0 & 1.67 & 0 & 11.33
\end{tabular}


AL-QADERY \& MUHIBBULLAH.

\begin{tabular}{lrrrrrrr} 
Chawkbazar & 48.33 & 20 & 8.33 & 5 & 5 & 1.67 & 0 \\
Khatungonj & 0 & 1.67 & 0 & 0 & 0 & 0 & 0 \\
Kadamtali & 1.67 & 0 & 0 & 0 & 0 & 0 & 0 \\
Dewanhat & 5 & 5 & 0 & 1.67 & 1.67 & 23.33 & 0 \\
Anderkilla & 0 & 0 & 1.67 & 0 & 0 & 0 & 0 \\
Oxygen & 1.67 & 0 & 0 & 0 & 0 & 11.33 & 0 \\
Badurtala & 0 & 1.67 & 0 & 0 & 0 & 0 & 0 \\
\hline
\end{tabular}

Impacts of traffic congestion

Traffic congestion is a common and daily event to the inhabitants of Chittagong metropolitan city. Table 4 shows the problems created by traffic congestion in the study area.

TABLE 4. DIFFERENT PROBLEMS CREATED BY TRAFFIC CONGESTION IN THE STUDY AREA.

\begin{tabular}{lcc}
\hline Problems type & Frequency* & Percentage* \\
\hline Air pollution & 270 & 93.10 \\
Sound pollution & 225 & 77.59 \\
Waste of time & 225 & 77.59 \\
Waste of money & 130 & 44.82 \\
Mental anxiety & 225 & 77.59 \\
Accident (Stroke, Death, Heart attack & 125 & 43.10 \\
etc.) & & \\
\hline
\end{tabular}

* Multiple answers were found by the respondent

Respondents generally presented more than one opinions. However, most of the respondents $(93.10 \%)$ have expressed their opinion that air pollution was the main problem caused by traffic congestion (Table 4). The other problems identified by the respondent's opinion are noise pollution $(77.59 \%)$, psychological strain $(77.59 \%)$, waste of time $(77.59 \%)$, waste of money $(44.82 \%)$ and accidents (43.10\%). These problems are affecting the road users' health, losing their valuable working hours and creating hypertension.

Satisfaction level of people about transportation system and management

The satisfaction level on transportation system of the study area was measured here to know the opinion about overall condition of transportation system of the city. Here, both index of satisfaction and percentages are used for 
PEOPLE'S PERCEPTION ON URBAN TRAFFIC CONGESTION

discussion. Table 5 shows index of satisfaction and ranking of satisfaction level from the respondents in the study area.

TABLE 5. SATISFACTION LEVEL AND RANKING ON TRAFFIC CONGESTION IN THE STUDY AREA.

\begin{tabular}{lrrrrc}
\hline Usable system & $\begin{array}{r}\text { Satisfactory } \\
(\%)\end{array}$ & $\begin{array}{c}\text { Average } \\
(\%)\end{array}$ & $\begin{array}{r}\text { Un satisfactory } \\
(\%)\end{array}$ & $\begin{array}{c}\text { Index of } \\
\text { satisfaction }\end{array}$ & Rank \\
\hline Road surface & 11.67 & 53.33 & 35 & -.23 & 1 \\
Road width & 8.33 & 38.33 & 53.33 & -.45 & 7 \\
Pedestrian facilities & 10 & 35 & 55 & -.45 & 7 \\
Traffic signals & 6.67 & 58.33 & 35 & -.28 & 2 \\
Traffic signs and markings & 13.33 & 36.67 & 50 & -.36 & 3 \\
Enforcement of traffic rules & 6.67 & 30.67 & 62.66 & -.55 & 9 \\
Performance of & 7.33 & 48 & 44.67 & -.37 & 4 \\
intersections & & & & & \\
Driver's behaviors & 9.67 & 27.33 & 63 & -.53 & 8 \\
Use of footpath & 16 & 29.33 & 54.67 & -.38 & 5 \\
Waste collection system & 13 & 30.67 & 56.33 & -.43 & 6 \\
Parking facilities & 6.67 & 29.67 & 63.67 & -.57 & 10 \\
\hline
\end{tabular}

All of the criteria involving transportation system and management of the study area are unsatisfactory. Among them, the worst condition was for parking facilities (-0.57) followed by enforcement of traffic rules (-0.55) and drivers behavior (-0.53). On the other hand, relatively better condition was for road surface (-0.23), traffic signal (-0.28) and performance of intersection (-0.37). So, it can be expressed that the over all quality of transportation system in the study area is not satisfactory.

Recommendations and mitigation policy of huge traffic congestion in Chittagong City

The following recommendations can be drawn from the present study:

1. To build up a well developed parking system in Chittagong Metropolitan City.

2. To enforce traffic rules appropriately.

3. To remove rickshaws and push carts from the city area.

4. To widen the roads.

5. To convert some roads to one way system.

6. To educate the people about traffic rules.

7. To take proper steps on training program for the vehicle drivers.

8. To train up traffic police for management.

9. To build up in the main points overpass/ underpass/zebra crossing. 
10. To restrict building of shopping centers, markets, educational institutions beside busiest roads.

11. To build up effective footpath facility.

12. To build up effective traffic island.

13. To dispose city wastes in proper places.

14. To take proper steps to prevent water logging.

\section{CONCLUSION}

The causes of traffic congestion and its consequences can not be addressed in isolation. Since Chittagong is dramatically changing its structure in terms of land use, transportation and urban facilities, it requires integrated planning and implementation of its system elements for sound and sustainable urban development. Sustainable development demands and policy innovations are necessary. An integrated planning of transport management policy must be formulated and implemented for this commercial city.

\section{REFERENCES}

1. ANONYMOUS 2003. New Advance Learners Oxford Dictionary. $14^{\text {th }}$ edition, New Delhi: Prentice-Hall of India, pp:133-134.

2. BBS (BANGLADESH BUREAU OF STATISTICS) 2007. Statistical Pocket Book of Bangladesh. Dhaka: Reproduction, Documentation \& Publishing Wing, pp:178-179..

3. BARUA, S. C. 2007. "Mitigation of Chittagong Congestion: Short and Long Term Proposal," The Daily Peoples View, 10 November: 5.

4. BRAIN, M. AND RICHARD, H. 1986. Modern Transport Geography, First edition, USA: University of Pennsylvania,734p.

5. CHOWDHURY, S. K. 1986. Country Paper of Bangladesh, Report of SAARC Seminar on Road Transportation and Safety, Dhaka; 10 December.

6. ISLAM, S. AND MIAH, S. ed. 2003. Banglapedia; National Encyclopedia of Bangladesh, Dhaka: Asiatic Society of Bangladesh, 9: 316-317.

7. KARIM, A. K. M. REZAUL, 2000. "An Integrated Planning to Remove Traffic Congestion and Air Pollution in Chittagong City", The Daily Star, 18 June: 4.

8. NISHAD, A. 2002. Bangladesh Environment, vol. 2, Dhaka: SEHD, pp:218219.

9. YEH, S. H. AND TAN, S. LEE. 1975. Satisfaction on Living Condition, Singapore: Singapore University Press Ltd.320p.

Manuscript received on 8.11.2008; Accepted on 22.11.2009

The Chittagong University Journal of Biological Sciences, Vol. 3( 1 \& 2): pp.149-160, 2008. 